\title{
Clinical profile of children with haemophilia at the University Hospital of Brazzaville
}

FO Galiba Atipo Tsiba, OL Ngolet, NY Ngakengni, LC Ollandzobo Ikobo, JV Nziengui-Mboumba, A Elira Dokekias

Introduction: Haemophilia is a rare hereditary haemorrhagic disease caused by coagulation factor VIII (haemophilia A) or IX (haemophilia B) deficiency. Very few data exist on this disease in Congo. This survey aims to describe the epidemiological and clinical aspects of the children affected. Materials and methods: A descriptive cross-sectional study was carried out in the haematology department of the Brazzaville University Hospital over a period

FO GALIBA ATIPO TSIBA

Haematology Department, University Hospital of Brazzaville; Faculty of Health Sciences, Marien Ngouabi University of Brazzaville, Congo. Email: atipogaliba@gmail.com

OL NGOLET

Haematology Department, University Hospital of

Brazzaville; Faculty of Health Sciences, Marien Ngouabi University of Brazzaville, Congo

NY NGAKENGNI

Paediatric Department, University Hospital of Brazzaville; Faculty of Health Sciences, Marien Ngouabi University of Brazzaville, Congo

LC OLLANDZOBO IKOBO

Paediatric Department, University Hospital of Brazzaville; Faculty of Health Sciences, Marien Ngouabi University of Brazzaville, Congo

\section{JV NZIENGUI-MBOUMBA}

Haematology Department, University Hospital of

Brazzaville, Congo

A ELIRA DOKEKIAS

Haematology Department, University Hospital of

Brazzaville; Faculty of Health Sciences, Marien Ngouabi

University of Brazzaville, Congo

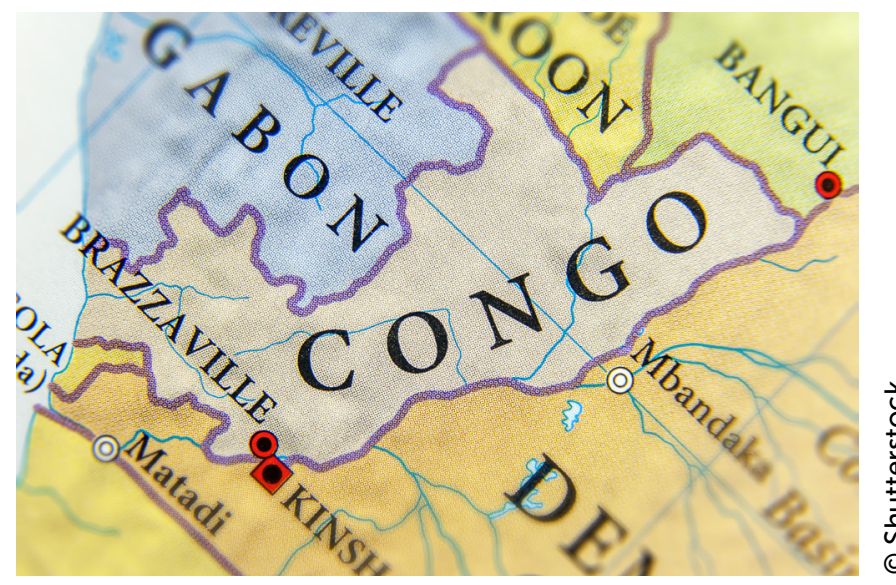

A descriptive study of children recently diagnosed with haemophilia at a hospital in Congo's capital city provides an epidemiological and clinical snapshot against a background where few data exist and the extent and impact of the disease is not yet known.

of two years. Children (under 18 years of age) with haemophilia and with a factor VIII or IX level less than or equal to $30 \%$ were identified. The parameters analysed included age, diagnostic delay, type and severity of haemophilia, type and frequency of bleeding manifestations, complications and history of transfusion. Results: Nineteen patients were identified with an average age at diagnosis of four years. The average time to diagnosis was six years, and the most frequent first known bleeding episode was haemorrhage during circumcision. Family history was found in 14 cases. There were 13 cases of haemophilia $A$ and six cases of haemophilia B. Fourteen cases were severe haemophilia; no mild cases were identified. Haemorrhagic manifestations included

This is an Open Access article distributed under the terms of the Creative Commons Attribution-NonCommercial-NoDerivs License (https://creativecommons.org/licenses/by-nc-nd/3.0/) which permits use and distribution in any medium, provided the original work is properly cited, the use is non-commercial, and no modifications or adaptations are made. Copyright is retained by the authors. 
haemarthrosis, haematomas and mucocutaneous haemorrhages. The average number of haemorrhagic episodes per year was 12 . Haemophilic arthropathy was present at diagnosis in seven cases, with the main location being the knee. The average number of hospitalisations before diagnosis was two. Sixteen patients had been transfused at least once. Conclusion: Although circumcision is the most frequent first known haemorrhagic manifestation of haemophilia in Congo, patients are often diagnosed late, sometimes with severe osteoarticular complications. Further measures are needed to help ensure early diagnosis and improve care.

Keywords: Children, haemophilia, circumcision, haemorrhage, arthropathy, Congo

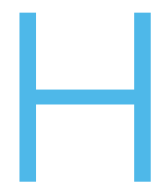

aemophilia is a hereditary haemorrhagic disease caused by a quantitative deficiency of coagulation factor VIII (haemophilia A) or factor IX (haemophilia B). It is transmitted in the recessive mode linked to the $X$ chromosome, and therefore mainly affects males. Its clinical expression is variable, ranging from profuse haemorrhages following minor trauma, to severe osteoarticular complications ${ }^{[1,2]}$. Its incidence in developed countries is estimated at 17 cases per 100,000 births for haemophilia $A$ and 6 cases per 100,000 births for haemophilia $B^{[3]}$. In many countries of sub-Saharan Africa, haemophilia remains an underdiagnosed disease. Although African countries represent around $18 \%$ of the global population, they represent less than $3 \%$ of patients diagnosed with haemophilia, only $2 \%$ of whom use clotting factor treatments ${ }^{[4]}$. Patients are most often seen late for several reasons, including ignorance of the disease, poor access to hospitals, and under-equipped laboratories ${ }^{[5-9]}$. World Health Organization figures indicate that in Congo there is a ratio of one physician and 8.2 nurses and midwives per 10,000 population ${ }^{[10]}$. Around two thirds of physicians and over $40 \%$ of allied health professionals are based in the city of Brazzaville, where around $37 \%$ of the population lives ${ }^{[10]}$.

In Congo, until 2016 the diagnosis of haemophilia was most often presumptive on the basis of a suggestive haemorrhagic symptomatology associated with an isolated prolongation of the activated partial thromboplastin time (aPTT; known locally as TCA or temps de céphaline activée). In some cases, diagnosis has been confirmed as a result of collaboration with laboratories located outside Congo. Since 2017, thanks to support from the Franco-African Alliance for the Treatment of Hemophilia (AFATH) and the World Federation of Hemophilia (WFH), the measurement of anti-haemophilia factors and the search for inhibitors are now achievable on site at the University Hospital of Brazzaville. Therefore, diagnosis is now quickly confirmed in suspected patients and new cases are regularly diagnosed.

Few data exist on the prevalence and clinical profile of haemophilia in Congo. Since 2017 the National Reference Centre for Sickle Cell Disease (CNRD) at Brazzaville University Hospital has served as a referral centre for the management of people with haemophilia. Thirty-four haemophiliac patients are now regularly monitored at CNRD, including nine adults and 25 children, 19 of whom are newly diagnosed.

Focusing on the children recently diagnosed with haemophilia in the hospital's Haematology Department, we aim to provide an initial snapshot of this health situation, describing epidemiological and clinical aspects. We hope that as the situation evolves, this will provide a point of reference and comparison for future studies.

\section{MATERIALS AND METHODS}

A descriptive cross-sectional study was carried out over two years (June 2017 - May 2019) in the Haematology Department of Brazzaville University Hospital, focusing on children (below the age of 18) whose haemophilia had recently been diagnosed. Diagnosis was confirmed by biological assay of factors VIII and IX with a semiautomatic Stago STart ${ }^{\circledR} 4$ device, where a factor level less than or equal to $30 \%$ was measured. Haemophilia was classified as severe when the factor VIII or IX level was less than $1 \%$; moderate when it was between $1 \%$ and $5 \%$; and mild when it was greater than $5 \%$ without exceeding $30 \%$.

Study data was gathered from medical records, as well as from interviews with patients and their families. The data analysed were epidemiological (age at diagnosis, type of haemophilia, family history), clinical (type and frequency of haemorrhagic manifestations before diagnosis, severity) and therapeutic (means used to manage haemorrhages), and also included medical history before diagnosis (number of hospitalisations and services involved). The pre-diagnosis complications sought included severe anaemia with need for blood transfusion, and osteoarticular damage such as joint arthropathy. The diagnostic period was defined as the period extending from the date of onset of the first known haemorrhagic manifestation to the date of actual diagnosis by laboratory investigation. 


\section{RESULTS}

The study identified 19 patients recently diagnosed with haemophilia. All children who were tested for haemophilia in the Haematology Department during the study period were diagnosed as having the disease.

The youngest patient at diagnosis was one month; the oldest was 16 years. Over two thirds were over five years of age at the time of diagnosis. There were 13 cases of haemophilia A and six cases of haemophilia $B$. Fourteen cases were classed as severe and five were moderate. There were no diagnoses of mild haemophilia. A familial history of haemophilia was found in 14 cases.

The mean average age of onset of the first known haemorrhagic manifestation was five months (1 month; 18 months). The average age at diagnosis was four years, although and the mean time to diagnosis was six years (3 days; 16 years). The most common first known bleeding episode was haemorrhage during circumcision, occurring in 12 of the 19 patients. The diagnosis of haemophilia was mentioned and established during circumcision in three patients. Haemophilic arthropathy was present at diagnosis in seven cases, with the main location being the knees (7/7), followed by elbows (5/7) and ankles (1/7). Among these seven patients, one joint (the knee) was affected in three cases, two joints (knee and elbow) were affected in two cases, and three joints (knee, elbow and ankle) were affected in two cases.

The mean number of bleeds per year was 12 (0; 24). Haemorrhagic manifestations included haemarthrosis, haematomas and mucocutaneous haemorrhages. Haemarthrosis was found in the knees, elbows and ankles. Some patients had more than one affected joint. Figure 1 shows an example of a swelling of the right knee related to haemarthrosis. Figure 2 shows a retractable scar that caused a wrist injury after a haematoma.

Treatment of bleeds most often consisted of the use of tranexamic acid (general and/or local; in 12 of 17 symptomatic patients). Three patients received fresh frozen plasma and two patients received cryoprecipitate on the recommendation of the Haematology Department; these patients had family history of haemophilia A or B. Haematoma incisions were made in two patients.

Due to significant bleeding with haemodynamic repercussions, 16 patients had received a transfusion of red blood cells at least once before being diagnosed with haemophilia. The mean number of transfusions per patient was $2(1 ; 5)$. The average number of hospitalisations before diagnosis was two $(0 ; 4)$. The services involved were paediatrics (two thirds of all hospitalisations) and surgical services.

Table 1: Parameters related to children diagnosed with haemophilia in the Haematology Department of Brazzaville University Hospital from June 2017 to May 2019

\begin{tabular}{|c|c|c|c|}
\hline & VARIABLE & NUMBER & FREQUENCY (\%) \\
\hline Gender & $\begin{array}{l}\text { Male } \\
\text { Female }\end{array}$ & $\begin{array}{l}19 \\
0\end{array}$ & $\begin{array}{l}100 \% \\
0\end{array}$ \\
\hline Age group at diagnosis & $\begin{array}{l}<1 \text { year } \\
1-5 \text { years } \\
>5 \text { years }\end{array}$ & $\begin{array}{l}3 \\
3 \\
13\end{array}$ & $\begin{array}{l}15.8 \% \\
15.8 \% \\
68.4 \%\end{array}$ \\
\hline Type of haemophilia & $\begin{array}{l}\mathrm{A} \\
\mathrm{B}\end{array}$ & $\begin{array}{l}13 \\
6\end{array}$ & $\begin{array}{l}68.4 \% \\
31.6 \%\end{array}$ \\
\hline Severity of haemophilia & $\begin{array}{l}\text { Mild } \\
\text { Moderate } \\
\text { Severe }\end{array}$ & $\begin{array}{l}0 \\
5 \\
14\end{array}$ & $\begin{array}{l}0 \% \\
26.3 \% \\
73.7 \%\end{array}$ \\
\hline $\begin{array}{l}\text { First known abnormal } \\
\text { bleeding }\end{array}$ & $\begin{array}{l}\text { Haemorrhage after circumcision } \\
\text { Haematoma } \\
\text { Oral haemorrhage }\end{array}$ & $\begin{array}{l}12 \\
6 \\
1\end{array}$ & $\begin{array}{l}63.2 \% \\
31.6 \% \\
5.2 \%\end{array}$ \\
\hline Circumstance of diagnosis & $\begin{array}{l}\text { Haemorrhage } \\
\text { Systematic screening }\end{array}$ & $\begin{array}{l}17 \\
2\end{array}$ & $\begin{array}{l}89.5 \% \\
10.5 \%\end{array}$ \\
\hline $\begin{array}{l}\text { Previous history of blood } \\
\text { transfusion }\end{array}$ & $\begin{array}{l}\text { Yes } \\
\text { No }\end{array}$ & $\begin{array}{l}16 \\
3\end{array}$ & $\begin{array}{l}89.5 \% \\
10.5 \%\end{array}$ \\
\hline Arthropathy at diagnosis & $\begin{array}{l}\text { Yes } \\
\text { No }\end{array}$ & $\begin{array}{l}7 \\
12\end{array}$ & $\begin{array}{l}36.8 \% \\
63.2 \%\end{array}$ \\
\hline
\end{tabular}


Figure 1: Swelling of the right knee related to haemarthrosis

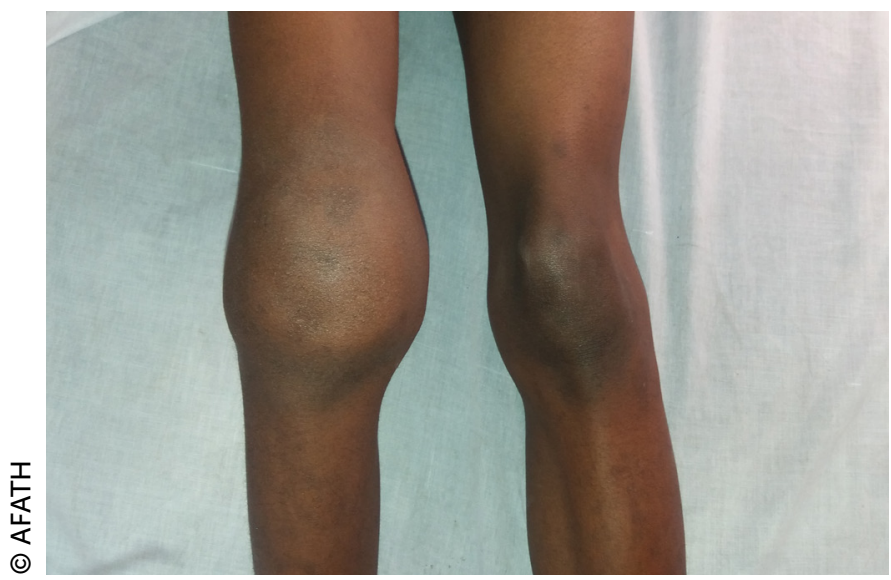

\section{DISCUSSION}

There are currently no statistical data on haemophilia in Congo. However, the WFH estimates that one child in 10,000 is born with haemophilia A and one in 50,000 is born with haemophilia $B^{[11]}$. Congo has a population of around 5.244 million (World Bank figure, 2018), meaning that there are likely to be over 500 people with haemophilia A and over 100 with haemophilia B in the country. As the population of Brazzaville represents over a third of the country's total population, we would expect a significant number of those to live in or around the city. Although focused on children under the age of 18 , the small sample size found in this study is reflective of poor access to patient care, which remains a major flaw in the Congolese healthcare system. The epidemiological situation of this disease remains to be revealed, and further surveys carried out across the various regions of the country would be beneficial in helping to identify people with haemophilia.

In common with what is described in the literature, the majority of patients in our study had type A haemophilia and severe forms were the most common ${ }^{[3,5-8,12]}$. The absence of mild forms in our context is probably explained by their lesser clinical expression. In mild haemophilia, haemorrhages are rarer and essentially post-traumatic ${ }^{[13]}$, and therefore the probability is low in our context for these patients to be referred to a specialist consultation. By contrast, the average number of bleeds per year for the patients in our study was 12, which cannot be considered to be a "rare" occurrence, and should raise questions even for doctors who are unfamiliar with haemophilia.

Haemorrhage occurring after circumcision represents the most frequent inaugural manifestation of the disease in Africa, and our results support those
Figure 2: Retractable scar and wrist flexion after incision of a haematoma of the forearm

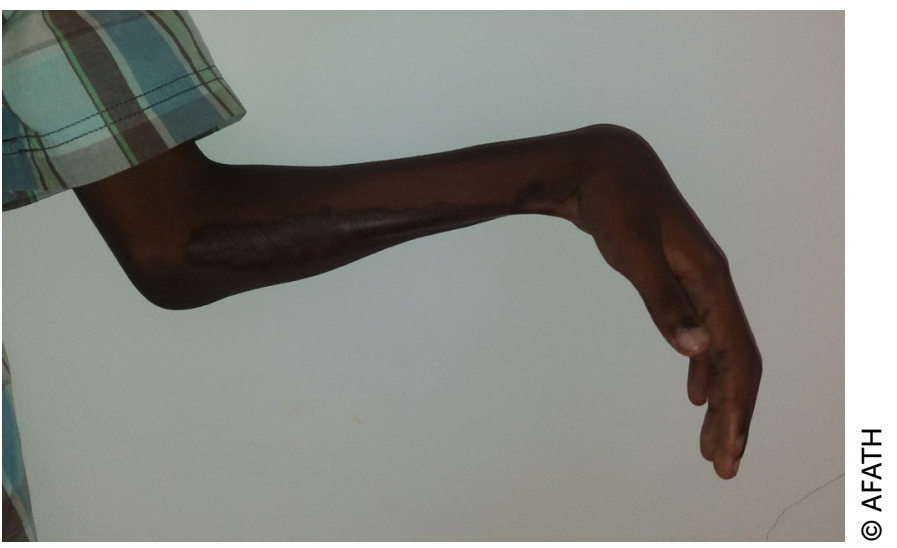

reported in other studies ${ }^{[6-8]}$. Circumcision would probably have accounted for a greater number in our study if it had not been the case that some parents hesitated to have their child circumcised because of a family history of haemorrhage. In most cases, there was no specialist consultation prior to circumcision, which helps to explain why the disease was very rarely diagnosed in this circumstance. In Congolese society, where the practice of circumcision is an ancestral tradition, it is therefore urgent to make nursing staff aware of the importance of systematically carrying out a haemostasis assessment before it is undertaken, and generally before any surgery, no matter how minor.

The medical journey of the patients covered a long time period. While the first haemorrhagic manifestations of the disease appeared at an average age of five months, the average age at diagnosis was four years. Delay in diagnosis is a well-known situation in Africa ${ }^{[5,7,8]}$ and it is not without consequences for the profile of the disease. Just over a third of patients in our study already had arthropathy at the time of diagnosis and, as reported in the literature, the ankles, knees and elbows were the main targets ${ }^{[6,8,12,14,15]}$.

The high rate of blood transfusion found in our study has also been reported in other series in Africa ${ }^{[7]}$. In the absence of replacement factor VIII or IX, transfusion was the main treatment option for a long time, even in diagnosed patients ${ }^{[7]}$. Since the 2010s, association with the WFH and the creation of multiple partnerships between referral centres in countries with limited resources and European hospitals have made it possible to strengthen local diagnostic capacities and improve patient access to treatment with factor replacement ${ }^{[16]}$.

In 2017 a partnership was established between the haematology department of Brazzaville University Hospital and AFATH, and the CNRD at Brazzaville 
University Hospital was equipped to allow the measurement of anti-haemophilic factors and the diagnosis of inhibitors. In addition, thanks to donations from the WFH humanitarian aid programme, ondemand treatment is possible most of the time for the treatment of haemorrhagic incidents (depending on factor availability). All patients included in the study had received factor to treat bleeding episodes at least once. For a little over a year, low-dose prophylactic treatment has been implemented (20 IU/kg every week for patients with haemophilia A and every 15 days for those with haemophilia B). But as expected, some patients have been diagnosed with inhibitors.

While this assistance has helped to bring some improvement in the care of people diagnosed with haemophilia in Congo, it remains insufficient and more government involvement is required to ensure the availability of anti-haemophilia factors.

Haemophilic arthropathy and inhibitors are the subject of work in progress with AFATH experts.

\section{CONCLUSION}

Haemophilia remains underdiagnosed in Congo. Although circumcision is the most frequent first known haemorrhagic manifestation, diagnosis is often late and patients sometimes already have joint complications, which can be severe. Assessing the particular determinants of diagnostic delay in Congo may help to establish measures that can help to ensure an early diagnosis of the disease and appropriate care, which in the long term could help to reduce complications linked to the disease. The relationship with the WFH and other partners has been important in helping to improve access to treatment, but further studies are required to identify undiagnosed people with haemophilia in Congo, and government support is needed to further improve care.

\section{ACKNOWLEDGEMENTS}

The authors have advised no interests that might be perceived as posing a conflict or bias.

This paper reports a retrospective study in which no human participants or animals are directly involved.

\section{ORCID}

FO Galiba Atipo Tsiba (iD https://orcid.org/0000-0002-4444-7547 OL Ngolet (iD https://orcid.org/0000-0001-8757-8136

\section{REFERENCES}

1. Franchini M, Mannucci PM. Past, present and future of hemophilia: a narrative review. Orphanet J Rare Dis 2012; 7: 24. doi: 10.1186/1750-1172-7-24.
2. Carcao MD. The diagnosis and management of congenital hemophilia. Semin Thromb Hemost 2012; 38: 727-34. doi: 10.1055/s-0032-1326786.

3. Iorio A, Stonebraker JS, Chambost H, et al; Data and Demographics Committee of the World Federation of Hemophilia. Establishing the prevalence and prevalence at birth of hemophilia in males: a meta-analytic approach using national registries. Ann Intern Med 2019; 171: 540-46. doi: 10.7326/M19-1208.

4. Diop S, Haffar A, Mahlangu J, et al. Improving access to hemophilia care in sub-Saharan Africa by capacity building. Blood Adv 2019; 3(Suppl 1): 1-14. doi: 10.1182/ bloodadvances.2019GS121537.

5. Diop S, Seck M, Sy-Bah D, et al. Implementing haemophilia care in Senegal, West Africa Haemophilia 2014; 20(1): 73-7. doi: $10.1111 /$ hae. 12249 .

6. Lambert C, Meité N, Sanogo I, et al. Haemophilia in Côte d'Ivoire (the Ivory Coast) in 2017: extensive data collection as part of the World Federation of Hemophilia's twinning programme. Haemophilia 2019; 25(2): 236-43. doi: 10.1111/ hae.13682

7. Tagny CT, Moudourou S, Ndoumba A, Mbanya D. Hemophilia in developing countries: an analysis of the first data in Cameroon, Africa. J Blood Lymph 2014; 4: 119. doi:10.4172/2165-7831.1000119.

8. Benajiba N, Boussaadni YE, Aljabri M, Bentata Y, Amrani R, Rkain M. Hémophilie: état des lieux dans un service de pédiatrie dans la région de l'oriental du Maroc. Pan Afr Med J. 2014; 18: 126. 10.11604/pamj.2014.18.126.4007.

9. Okoye HC, Korubo KI, Nwogoh B, Efobi CC, Ugwu NI, Madu $A J$. Challenges in the management of bleeding disorders in Nigeria. Niger J Clin Pract 2018; 21: 468-72. doi: 10.4103/njcp. njcp_319_17.

10. Global Health Workforce Alliance. Reviewing progress, renewing commitment: progress report on the Kampala Declaration and Agenda for Global Action. Global Health Workforce Alliance. World Health Organization, 2011. Available from https://www.who.int/workforcealliance/knowledge/ resources/kdagaprogressreport/en/ (accessed 17 April 2020).

11. World Federation of Hemophilia. Introduction to hemophilia. Available from https://elearning.wfh.org/elearning-centres/ introduction-to-hemophilia/ (accessed 20 April 2020).

12. Mou XL, Zhao Y, Chen ZH, Ding YQ, Li M, Jia MF, Xi YM. [Clinical characteristics of 223 Chinese patients with hemophilia in a medical center of Gansu Province in China] Zhongguo Shi Yan Xue Ye Xue Za Zhi 2016; 24(5): 1495-99. doi: 10.7534/j.issn.1009-2137.2016.05.038.

13. Kulkarni R, Soucie JM, Lusher J, et al.; Haemophilia Treatment Center Network Investigators. Sites of initial bleeding episodes, mode of delivery and age of diagnosis in babies with haemophilia diagnosed before the age of 2 years: a report from The Centers for Disease Control and Prevention's (CDC) Universal Data Collection (UDC) project. Haemophilia 2009; 15: 1281-90. doi: 10.1111/j.1365-2516.2009.02074.x

14. Aronstam A, Rainsford SG, Painter MJ. Patterns of bleeding in adolescents with severe haemophilia A. Br Med J 1979; 1: 469-70.

15. Pergantou $H$, Matsinos G, Papadopoulos A, et al . Comparative study of validity of clinical, $X$-ray and magnetic resonance imaging scores in evaluation and management of haemophilic arthropathy in children. Haemophilia 2006; 12(3): 241-7. 
16. Pierce GF, Haffar A, Ampartzidis G, et al. First-year results of an expanded humanitarian aid programme for haemophilia in resource-constrained countries. Haemophilia 2018; 24(2) 229-235. doi: 10.1111/hae.13409.
HOW TO CITE THIS ARTICLE:

Galiba Atipo Tsiba FO, Ngolet OL, Ngakengni NY,

Ollandzobo Ikobo LC, Nziengui-Mboumba JV, Elira

Dokekias A. Clinical profile of children with haemophilia at

the University Hospital of Brazzaville. J Haem Pract 2020;

7(1): 53-58. https://doi.org/10.17225/jhp00159

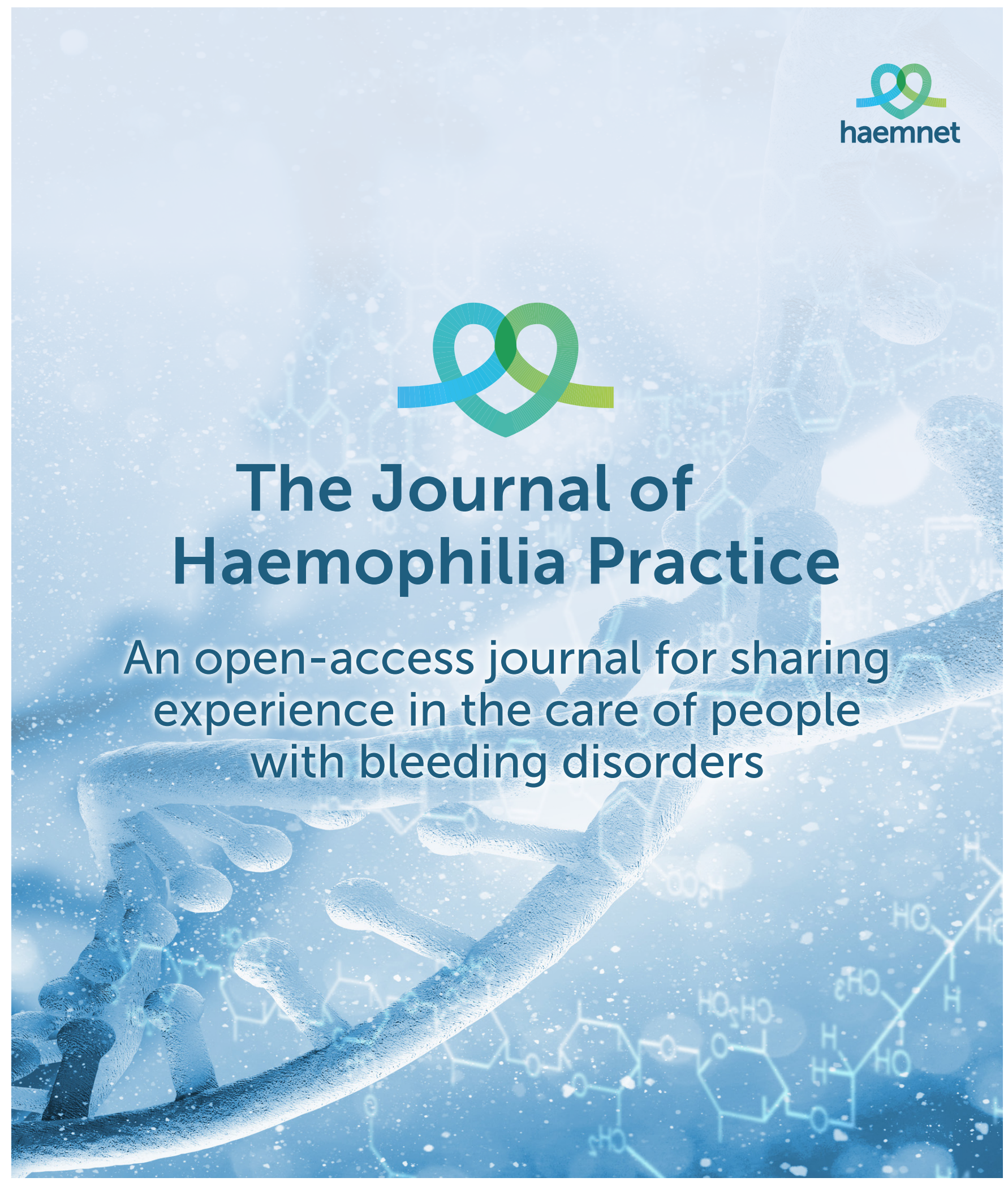

